\title{
On philosophy and schizophrenia: the case of thought insertion
}

\author{
Jasper Feyaerts \& Wouter Kusters
}

When we do philosophy, we should like to hypostatize feelings where there are none. They serve to explain our thoughts to us.

Wittgenstein, Investigations, 598

\begin{abstract}
Philosophers have often turned towards schizophrenic experience as a way to empirically substantiate philosophical assumptions regarding the essential nature of selfhood. In this context, the phenomenon of thought insertion (TI) has served as a particularly privileged example, as it is assumed to reveal, in a pathological or negative way, the nature of ordinary self-experience. In this paper, we critical discuss one such philosophical account that attempts to explain thought insertion as involving a loss of a 'sense of agency' that is presumed to characterize ordinary thinking. In the second part, we furthermore critically revisit the more general assumption that schizophrenia can be understood as a 'via negativa' into overlooked evidences and experiences that would permeate ordinary life. Instead, we advance the idea that both philosophy and schizophrenia share a basic kind of hyper-reflexive attitude towards ordinary life. In conclusion, we detail the implications of this idea for current accounts of thought insertion and sketch the general lines of an alternative model that puts more emphasis on the shared nature of philosophical and schizophrenic reflection, and the dialectical paradoxes that may arise in such reflection.
\end{abstract}

\section{Introduction}

The relation between philosophy and schizophrenia is intimate and complex (Sass 1992; Strassberg 2014; Kusters 2020). On the one hand, it seems that schizophrenia, perhaps more than other forms of psychopathology, entails a form of experience in which traditional philosophical issues can become the explicit object of questioning perplexity and existential concern (Blankenburg 1971; Humpston \& Broome 2016). This is apparent, for example, in the often ontological, cosmological or metaphysical cast of the delusions that are considered characteristic of the condition (Sass 1992; 1994; Bovet \& Parnas 1993; Feyaerts et al. 2021).

Yet, it also seems that schizophrenia itself, perhaps also more than other psychopathological categories, often figures as the privileged object of philosophical reflection (Woods 2011). Importantly, this philosophical fascination with schizophrenia includes but also 
goes beyond a mere application of philosophical concepts in order to enhance our psychopathological understanding (concepts such as self-consciousness, intentionality, voluntary action, subjectivity, etc.). It also derives from the common assumption that schizophrenia - and some of its prototypical symptoms (e.g., delusions, hallucinations, firstrank symptoms, ...) - may be able to teach us something about the nature and meaning of these philosophical concepts themselves.

One area of current research in which this particular interplay between schizophrenia and philosophy has been expressed most clearly is in the analysis of thought insertion (henceforth: TI). In this symptom - whose presence was once regarded sufficient for the diagnosis of schizophrenia (see Schneider 1959; Nordgaard, Henriksen, Berge \& Nilsson 2019) - patients typically report that their thoughts are in some puzzling sense no longer their 'own'. Determining the purported psychopathological 'essence' of this symptom, and specifically, of the sense of depersonalization it involves, has become the recurring focus of a substantial stream of philosophical literature (e.g., Billon 2013; Bortolotti \& Broome 2009; Gallagher 2015; Ratcliffe \& Wilkinson 2015; Henriksen, Parnas \& Zahavi 2019 - for a comprehensive overview, see López-Silva 2018).

However, as noted above, this philosophical interest has been only partly clinically motivated. The case of TI has, in addition, often functioned as a kind of real-life thought experiment on the basis of which various philosophical intuitions regarding the nature of selfawareness, subjectivity or (mental) agency are presumed to be possibly vindicated. ${ }^{1}$ The central assumption here is that TI, and schizophrenia more generally, offers philosophers an empirical contrastive condition that can help to shed light on implicit aspects of normal self-experience that normally remain hidden - but whose existence (in normal conditions) is revealed precisely by the fact of their absence in certain abnormal conditions. ${ }^{2}$ Freud viewed dreams as offering

\footnotetext{
${ }^{1}$ Incidentally, this specific philosophical use of psychopathology is perhaps one of the main reasons why most authors within this literature are content on analyzing only a handful of clinical examples, which, furthermore, are artificially abstracted from the wider clinical Gestalt in which they occur. For an elaboration of this critique and its ramifications, see Henriksen, Parnas \& Zahavi (2019). We will return to this point at the end of our chapter.

${ }^{2}$ For various formulations of this same central assumption, see, e.g., Ratcliffe (2008: 483): "It is not just a matter of applying phenomenological discoveries in the context of psychopathology. We can also study the structure of experience by engaging with the ways in which it can be altered. Ordinarily overlooked aspects of experience become salient when we are presented with their loss, exaggeration or distortion"; Parnas \& Zahavi (2000: 11): "The normal is often so familiar to us that it remains practically unnoticed; it is so pervasive that it becomes elusive. [...] However, exactly because psychopathological disorders involve such profound deviations from normal human experience, they can bring forth usually taken-for granted, unnoticed conditions of normal daily experience".
} 
the royal road to the unconscious; in somewhat analogous fashion, TI is thought to reveal the nature of our self-experience in its elusive dimension of lived immediacy. ${ }^{3}$

This chapter has two main aims. In the first part, we will critically discuss one prominent philosophical account that attempts to explain TI as involving a loss of a 'sense of agency' that is presumed to characterize ordinary thinking (cf. Gallagher 2015). After providing a brief overview of the discussion surrounding this phenomenological description, we will use Wittgenstein's expressivist understanding of first-person authority to resist the idea that TI, and concepts like the self, thinking and agency more generally, can be relevantly clarified in terms of a phenomenological focus on 'experience'.

In the second part, we make use of this sense of agency-account as a paradigmatic example that can allow us to critically reconsider the more general idea that TI offers philosophical accounts a kind of pathological 'via negativa' into evidences and experiences that would normally permeate ordinary life. Instead, drawing on Sass (1992/2017) and Kusters (2020), we will develop the alternative idea that both philosophy and schizophrenia share a basic kind of attitude towards ordinary life, which in the case of TI is exemplified by a preoccupation with, and reflection on, the very question of the ownership and origin of thoughts and experiences. In conclusion, we detail some of the implications of our discussion for current accounts of TI and related phenomena.

\section{Thought insertion and the phenomenological grounds of self-experience}

Early discussions of TI invoked the phenomenon of thought insertion as an alleged counterexample to longstanding Cartesian intuitions regarding the infallibility of certain forms of selfconsciousness (Campbell 1999, Gallagher 2000; Coliva 2002). TI was viewed as possibly challenging the seemingly self-evident fact that, whenever we are conscious of our thoughts, we are (supposedly) also immediately conscious of these thoughts as our thoughts. Sometimes this latter is held to be a necessary or logical truth; sometimes more as a universal empirical finding. Philosophically, this principle is often discussed in terms of the technical notion of “immunity to error through misidentification" (Shoemaker 1968) - which means, less

\footnotetext{
${ }^{3}$ In line with this idea, some have drawn a close parallel between Husserlian phenomenology, and particularly its 'unnatural' methodological tool of epochè, and schizophrenia. Both are considered to involve a kind of revelatory detachment from one's experiences which are henceforth no longer simply lived through, but instead become open to reflection and analytic scrutiny - the former, however, by methodological fiat, the latter, qua existential predicament (see Depraz 2003; Stanghellini 2004).
} 
technically, that in first-person ascriptions of thought, we simply cannot be mistaken about who is thinking, since to do so would be empathically unintelligible or perhaps even logically inconceivable (cf. Jaspers 1962; Roessler 2013). Examples of TI would seem, however, to contradict even this last vestige of Cartesian certainty. One of Jaspers' patients describes such an experience:

I have never read nor heard them [such thoughts]; they come unasked; I do not dare to think I am the source but I am happy to know of them without thinking them. They come at any moment like a gift and I do not dare impart them as if they were my own (Jaspers 1963: 123).

Since such reports seem to deny what is widely considered a necessary feature of our conscious lives - i.e., what Jaspers termed "this particular aspect of "being mine", "of having an I-quality" - he famously held them to be "incomprehensible" and as "in principle psychologically inaccessible to us".

Yet, to deny reports of TI any form of intelligibility has become a minority position today. The currently preferred approach is to attempt to understand such reports by offering a more careful specification of the particular aspect of the sense of subjectivity that they appear to be lacking. This strategy here involves distinguishing between two distinctive ways in which thoughts can subjectively be experienced as one's own: that is, in terms of a sense of 'ownership' versus one of 'agency', and then by claiming that, whereas the former is preserved in experiences of TI, the latter is absent.

The 'sense of ownership' is meant to refer, in this context, to the fact that thoughts are not only experienced, but experienced as being experienced by me, that is, experienced as occurring as part of my own stream of experience. This 'sense of ownership' is also described in terms of the 'mineness' or 'for-me-ness' that, presumably, would characterize all forms of conscious experience. This is the idea that, regardless of the type of mental episode I am currently enjoying - e.g., whether I intend to drink my morning coffee or think that drinking coffee would be an excellent thing to do -, such episodes all include and share a certain qualitative or phenomenal character or feel (i.e., a what-it-is-likeness) that individuates me as the subject or experiencer of these episodes. Moreover, this subjective character is not taken to consist in some additional 'quale' or 'feature' attached somehow to the content of experience, but rather in the very way such experiences are given to me: namely, in a specifically first-personal rather than thirdpersonal manner of appearing. As Gallagher and Zahavi (2005/2014) put it: 
As I live through these different experiences, there is something experiential that is, in some sense, the same, namely, their distinct first-personal character. All the experiences are characterized by a quality of mineness or for-me-ness, the fact that it is I who am having these experiences.

The 'sense of agency', on the other hand, is meant to refer to the experience of being the active agent or author of certain thoughts. The idea here is that thinking (just like deliberating, planning or calculating) is a form of mental activity or action, and that the phenomenology of such active thinking is normally accompanied by a pre-reflective or first-order feeling of agency that individuates me as its agent or author. This pre-reflective, agentive feeling is considered to be the phenomenological basis for second-order or self-directed attributions of actions to myself as the agent of the action in question. By contrast, in cases of reflex movement or, e.g., when some other person pushes me, I would presumably lack the underlying feeling of agency necessary to self-attribute these movements as actions that are intentionally undertaken or performed by myself.

Armed with this phenomenological distinction, it seems possible to avoid Jaspers' conclusion that reports of TI must be fundamentally 'incomprehensible' in the sense of lying beyond the pale of either rational or empathic comprehension. If we assume (i) that thinking is normally a form of voluntary (mental) action, which (ii) is accompanied by a feeling of agency, and (iii) that expressions of thought constitute linguistic reflections of this phenomenological reality, then reports of TI can be considered - qua experience claims - as structurally similar to examples of involuntary movement or reflex behavior: namely, as instances when thoughts do occur to me, but seem just to happen rather than to be actively entertained.

It may well seem that the 'sense of ownership' is always retained in instances of TI: a patient complains, after all, that it is she who has to endure the alienating passivity of thoughts and not someone else. This would seem to acknowledge that she still 'owns' these autonomous thoughts as an experiencing subject, even as she denies being the active agent of thoughts that seem to occur regardless of her personal intentions or volitional activity.

Such a phenomenological interpretation of TI has at least one clear advantage: what patients tell about their experiences need not be interpreted as remaining closed to meaningful understanding (eg, Berrios 1991). Indeed, on this interpretation, the claim of TI concerns a perfectly coherent as well as truthful avowal. Since the disruption of agency presumably does occur on the pre-reflective level of experience, reports of TI can be considered as being, at least in part, accurate descriptions that are grounded in this altered sense of agency, and this validates the value and cogency of the first-person perspective of the patient. 


\section{Questions and critique}

However, this sense-of-agency account of TI has not remained unchallenged. Indeed, there are a variety of critiques (for a summary of these and a response, see Gallagher 2015), including the following. It is argued:

1. that TI should in fact be described as a disturbance in our 'sense of ownership' rather than 'agency', so long as the former is conceived appropriately: i.e., not in terms of spatial metaphors according to which 'my' thoughts occur within 'my' field of consciousness, but in terms of whether someone wants or is able to endorse the corresponding thought contents (see Bortolotti \& Broome 2009);

2. that the agentive problem is not situated at the level of immediate pre-reflective experience, but on the level of reflective or narrative attribution (Campbell 2001);

3. that the description of TI in terms of a disturbed sense of agency is insufficient to distinguish inserted thoughts from, for example, obsessive thoughts (Billon 2013);

4. that the phenomenological description fails to take into account the specific contents of thoughts that are experienced as ego-dystonic (López-Silva 2018); or finally

5. that most or all thinking is itself (as Nietzsche once emphasized) not really an activity, but instead a predominantly passive phenomenon ("a thought comes when 'it' wants to and not when 'I' wish" - Nietzsche 1886: 17; see Strawson 2003).

There is, however, an assumption that remains implicitly accepted throughout these various critiques; and this is the more general philosophical assumption that concepts like thinking, agency, or ownership can all be relevantly clarified in terms of a phenomenological focus on experience. While authors differ, for example, on whether it is the sense of agency or the sense of ownership that is the most salient feature in TI, the very idea that such experiential senses or feelings must and do play a crucial role in ordinary thought goes unquestioned. Again, while there are different views on how our normal experience of thought should best be described (e.g., as active, passive, marked by 'mineness', ...), the very assumption that thinking is to be understood or conceived as being, in its essence, an experiential phenomenon, a form of lived experience, is taken for granted. This experiential assumption is also evident in the proposed interpretations of TI: what is considered strange about reports of TI is not primarily their selfdirected preoccupation with the supposed 'experience' of thought processes, but rather, the anomalous or unusual nature of that experience. A similar emphasis can be gleaned from Jaspers' description of schizophrenic self-alienation: "The remarkable thing about this particular phenomenon is that the individual, though he exists, is no longer able to feel he exists. 
Descartes' 'cogito ergo sum' (I think therefore I am) may still be superficially cogitated but it is no longer a valid experience" (1963: 122 - our emphasis).

We will argue, however, that this generalized emphasis on self-experience --- that is, in the well-known phrase, on 'what-it-is-like' to think, to be active, to be a self, derives less from actual phenomenological findings regarding the experiential nature of these concepts, than from a questionable philosophical interpretation of the phenomenon of first-person authority - that is, of our seemingly effortless ability to say what we think, feel, want, or believe (see also Feyaerts \& Vanheule 2017). To clarify these issues we will, in the following section, revisit the nature of this notion of first-person privilege and will consider the contrasting philosophical interpretations it has received in the phenomenological tradition and by Wittgenstein respectively. On the basis of comparison, we will question the idea that concepts like thinking, agency or ownership need refer to, or be defined by, phenomenological experiences, and will develop some of the implications of this critique for philosophical accounts of TI.

\subsection{How do I know what I think?}

The basic intuition which is captured by notions like first-person authority or first-person privilege is that, all things being equal, I am usually the best person to ask if you want to know what I think, feel, intend, and so on. Other classical examples of such privileged mental concepts are those that are usually invoked to put an end to philosophical temptations toward skepticism. Thus, for example, while according to Descartes, I can conceivably be mistaken about whether I'm really taking a walk or writing a text, such skeptical doubts cannot meaningfully extend to whether I believe this is so, whether it seems to me that way, or whether I judge it to be so. These typical cogitatio ${ }^{4}$ are all members of a larger class that Wittgenstein designated as "psychological verbs". Amongst these psychological verbs, we find those which indeed point towards experiences ("I see", "I hear", "I have a headache"), but also cognitive activities ("I think", "I judge"), intentions ("I'm going to", "I propose to") and acts of the will ("I’ve decided to", "I want to").

\footnotetext{
${ }^{4}$ As noted by several commentators, Descartes' uses the words "cogitation" and "cogitare" in both an extended as well as a more restricted sense compared to our current understanding of these notions in the sense of "thinking" or "cognition". Extended because they also comprise, for example, acts of imagination, sensing and willing. Restricted because Descartes retains only those acts which are immediately and infallibly 'given' in consciousness. See Descombes (2004: 176-189), Anscombe (1981) and Narboux (2019).
} 
Secondly, our 'subjective privilege' with regard to these psychological verbs basically consists in being exempt from the demands of verification or evidence that are usually attached to our ordinary acts of judgment, which can be denied, contradicted, or at least questioned about their justification. This is the feature Wittgenstein (2009) had in mind when he spoke of "asymmetry of the first and third persons in the present indicative". That is, if, for example, I claim that "I lost my wallet" or that "I broke my arm", then the reasons I would cite in order to justify these claims would be the same kind of reasons as would apply if I were to say this of someone else: roughly, reasons pertaining to observation, testimony or inference. Hence, with respect to their justification, in these cases there is no asymmetry between the first-personal statement "I lost my wallet" and its third-personal version "He lost his wallet" - both are justified by, for example, checking one's own or someone else's pocket.

However, when I claim that I want to eat a pizza bianco, am thinking about Freud's Future of an Illusion, or desire to go on a holiday, that similarity to the third-person vanishes. Clearly, there does seem to be something strained and misguided about someone asking me to justify these claims (e.g., "so you're thinking about Freud's writings - ok, but how do you know you are?"). And if I were nonetheless tempted to cede to such queries, citing behavioral evidence or inferences-to-the-best-explanation to the effect that I really am contemplating Freud's writings, this would seem to make matters worse. As Wittgenstein points out, an important feature of the apparently incorrigible character of self-ascriptions deploying psychological verbs in the present indicative is that one cannot ask the person how he knows. By contrast, the third-personal claim that someone else is contemplating Freud's writings lacks such privileges and is in principle susceptible to further demands of justification.

Yet how, in fact, should we explain this remarkable capacity to talk in such an authoritative way about our present thoughts, hopes and fears? Here it will be instructive to contrast Wittgenstein's treatment of this topic with the one we typically find in the phenomenological tradition.

To begin with the latter: phenomenological approaches typically try to explain first-person authority by invoking some special mode of first-personal access or givenness that allows the subject of these mental states to know about them. That is, phenomenology takes the problem of first-person authority to be one specific version of the more general epistemological question of knowledge - in this case involving 'self-knowledge' - and the problem is therefore, as befits such epistemological queries, that of determining the origin and conditions of possibility of that knowledge. The implicit reasoning behind this idea seems to be the following: In the same way as I would be unable to say of this particular object that it is a table if I did not first recognize 
it as a table, I would not be able to say, for example, that I want to watch Better Call Saul if I did not first recognize a mental state as one of me-wanting-to-watch that series. Therefore, in order to explain the possibility of authoritative psychological statements, it is considered necessary to invoke a phenomenon of 'experiential evidence' for, or 'givenness' of, my mental states. As Zahavi argues in the case of beliefs and intentions:

[...] if I am to deliberate on and access my beliefs and intentions, it is not enough that I have them: I must also have been aware of them; that is, prior to reflection I cannot have been 'mind-blind'. Reflection is constrained by what is pre-reflectively lived through. It is answerable to experiential facts and is not constitutively self-fulfilling. To deny that the reflective self-ascriptions of beliefs is based on any experiential evidence whatsoever is implausible. It is to deny that such selfascriptions amount to a cognitive achievement (2014: 36).

Now what it is that provides this 'experiential evidence,' the source of "a cognitive achievement," is something about which, even in the phenomenological tradition, a variety of views exists. Here we will only focus on the approach that underlies the sense-of-agency account and that is most commonly associated with Husserl or Sartre. This approach basically consists in stating that psychological verbs like thinking, perceiving or doubting are all "acts of consciousness".

In keeping with Brentano's definition of mental phenomena, such acts of consciousness are said to be intentional, i.e., acts through which I am immediately conscious of something. Perception, for example, is that 'mode of consciousness' through which a perceptual object appears; imagination, that mode of consciousness through which something is given as imagined; thinking, that by which something is thought. Therefore, on this approach - and in contrast, for example, to introspective or higher-order theories - one does not say that my intention to go on a holiday is something I 'perceive' or 'represent' by way of a further act, but rather that my intention is a 'consciousness' of a future holiday in the very way of intending it. Similarly, one does not say that my desire for a bloody mary is something I apperceive as a disinterested spectator, but rather that this desiring involves a mode of consciousness through which a bloody mary appears as desirable. One has to distinguish, as Husserl (1976: 303-4) put it, the cogitatum from its cogito, the intentional object as it is intended, specified, or determined in its nature as an object (im Wie seiner Bestimmtheiten) from the intentional act through which it is intended or given (im Wie seiner Gegebenheitsweisen).

In other words, it is through my transitive or 'thetic' consciousness of, say, a burning house as perceived or imagined, that I am immediately aware of the intransitive or 'non-thetic' presence of an act of perception or of imagination. Importantly, it is only because these 
intransitive acts through which I am consciously related to objects are themselves also 'experienced' (which means that there is something 'it-is-like' to perceive, believe, think or intend), that I am subsequently able to report on these acts and their intentional objects whenever I'm asked. To use the typical phenomenological neologisms for denoting this kind of intransitivity: such pre-reflective experiences are said to be 'intrinsically self-revealing', 'self-disclosing', 'pre-reflectively self-given' or 'self-manifesting' (for these ideas, see Henry 1973) - in short: it is in their very nature to provide their own evidence. And therefore, insofar as my ability to report on them is explained by their 'self-revealing' character, all such acts of consciousness are considered to have a distinctive phenomenology about them. As Zahavi writes:

it is the conscious states themselves [e.g., perceiving, believing, thinking, ...], and not some internal observation of them, that provide part of the justification for any subsequent selfascription of those very states. In short, the fact that the phenomenally conscious states are already like something for the subject is what makes those very states capable of playing a justificatory role vis-à-vis any higher-order belief regarding their very existence" (2014: 36 - content within brackets added)

To sum up: as we argued above, we see that the phenomenological approach tends to treat all psychological concepts as one generic class of 'experience concepts', and that this is motivated by the attempt to explain our first-person authority in terms of some form of 'intrinsic' or 'prereflective' experiential access. Since this first-person authority not only extends to sensing a pain in one's shoulder, but also to the fact of remembering something or thinking certain thoughts, and throughout all these examples, that it is $I$ who feels, remembers or thinks, it becomes tempting to invoke justificatory 'I-feelings', 'experiences of thought' or 'senses of agency' as the phenomenological ground for my self-attributions. For the same reason, it becomes tempting to explain reports of TI in terms of the alteration or loss of such justificatory I-feelings.

However, if we now turn to Wittgenstein's discussion of first-person authority, we find a markedly different approach, one that questions the felt necessity, and even intelligibility, of positing all kinds of experiences to explain our self-ascriptions of psychological concepts. Wittgenstein's way of addressing this problem begins with the simple suggestion that our selfascriptions owe their status, which is so apparently authoritative, to the fact that they are not reports or experiential descriptions of our current psychological 'states', but rather count as expressions of the states that, in fact, they only appear to describe based on a superficial 
consideration of their surface grammar. In the case of sensation-language - e.g., statements about pain -, Wittgenstein puts this point as follows:

What I do is not, of course, to identify my sensation by criteria: but to repeat an expression. But this is not the end of the language-game: it is the beginning.

But isn't the beginning the sensation - which I describe? - Perhaps this word "describe" tricks us here. I say "I describe my state of mind" and "I describe my room." You need to call to mind the differences between the language games $(2009, \S 290)$

What are "the differences between the language-games" at issue here, that is, between describing one's room and describing one's state of mind, that Wittgenstein is hinting at in this quote? An important point seems related to - if we can put it that way - the 'temporal logic' of the descriptive assertion. Wittgenstein appears to be intent on denying that in the case of, for example, saying that I am in pain, I should begin with the examination of my pain-sensation before proceeding to the self-ascription; whereas, in the case of describing my room, it is of course indispensable that I should have observed things and looked it over before engaging in my description. In the latter case, the description comes at the end of the language game - after I have identified, e.g., whether the room is spacious or contains a chaise longue. Moreover, this is what in fact justifies my descriptive assertion.

Yet if Wittgenstein denies that this is what we ordinarily do when we offer our thoughts on some issue or complain about a pain in our back, then what is it that justifies these firstpersonal ascriptions? And what does it mean that in this kind of language game such ascriptions come first, rather than at the end of some justification? To continue the analogy with the roomdescription: one might think, for example, that to begin with the ascription would actually amount to describing one's room without looking at it first, that is to say, to simply engage in some highly speculative endeavor. And since, in fact, Wittgenstein abrogates epistemic justifiers in the case of psychological self-ascriptions, this seems to leave us with the following option: to construe such talk as being merely the result of - to use Dennett's expression - some “impromptu theorizing" (1991: 67), i.e., as groundless fictional assertions about putative mental items. However, that this is not the conclusion Wittgenstein wants to draw becomes clear in the following passage:

When I say 'I am in pain' I am at any rate justified before myself." - What does that mean? Does it mean: "If someone else could know what I am calling 'pain,' he would admit that I was using the word correctly"?

To use a word without a justification does not mean to use it wrongfully (2009: §289) 
So, according to Wittgenstein, it is not because I am not "justified before myself" in saying that I' $m$ in pain, that I am therefore unjustified when resorting to this pain-talk in the sense of making a mistake or simply talking nonsense. The opposition between being epistemically justified or unjustified is then, in fact, a false opposition that does not allow us to explain what is distinctive about our first-personal ascriptions of pains or beliefs. That is, to rid oneself of the idea that, in order to avoid skeptical worries about our ordinary 'folk-psychological' practices, authoritative psychological self-ascriptions of thoughts, beliefs and sensations must be grounded in experiential evidence, we have to question the assumption that first-person avowals function as judgements and reports about psychological facts the speaker has previously learned or ascertained. This is the guiding thought behind Wittgenstein's following remarks:

The paradox disappears only if we make a radical break with the idea that language always functions in one way, always serves the same purpose: to convey thoughts - which may be about houses, pains, good and evil, or whatever" (2009: §304)

When someone says "I hope he'll come", is this a report [Bericht] about his state of mind, or a manifestation [Äusserung] of his hope? - I may, for example, say it to myself. And surely I am not giving myself a report (2009: §585)

Here we retrieve the earlier suggestion that psychological utterances are primarily manifestations or expressions of the very states or activities they self-ascribe, rather than secondary thoughts or beliefs about these states or activities uttered to inform the listener about their presence. Therefore, utterances like "I am in pain" or "that really hurts!" are not painreports on a par with weather-reports, but rather, like my moans and cries, manifestations of my pain; similarly, the utterance "I want to go out" does not inform someone about some planning experience, but voices, depending on the context in which it is said, my desire to go out or my agreement to your proposal; in the same way, ardent exclamations like "I love you" or "I really hate your guts" do not communicate subjective facts to which you may or may not agree or proceed to inquire some further information, but should be more properly understood as verbal equivalents of bringing flowers and throwing plates in your direction.

Now, to conclude this section: what is the philosophical import of Wittgenstein's expressivist understanding of first-person authority and how precisely does it differ from the phenomenological approach we discussed? Furthermore, what are the implications of this discussion for the sense of agency-account of TI, and more generally, for the ways in which we try to make sense of reports of TI? 
First, we noted that the phenomenological temptation to posit all sorts of experiences (e.g., a feeling of mineness, a sense of agency, ...) to explain our first-person authority results from conceiving I-statements of thoughts, actions or intentions as descriptive or self-referential reports about our thoughts, feelings and intentions. Wittgenstein's expressivist treatment of first-person authority, by contrast, offers us reasons to resist this temptation. On Wittgenstein's approach, what explains our authority in saying what we think or believe is not that we ordinarily dispose of pre-reflective evidence for our thoughts and beliefs, but rather that our psychological statements ordinarily count as manifestations of those thoughts and beliefs. This means that, contrary to the phenomenological effort to supply various experiential grounds to justify our psychological utterances, there is no epistemic question to be answered about how I am able to offer my thoughts or to communicate my intentions, because such utterances do not involve subjective judgments about the presence of such thoughts or intentions in the first place. What, instead, might justify a thought like "I think I have a flat tire" or my intention "to change it" would, on occasion, have nothing to do with me (e.g., my experience of thinking or intention), but rather with something occurring in the world (e.g., a warning signal in my car). In short, expressive psychological statements are not statements about the psychology of the speaker, and neither are they justified by the psychology of the speaker.

Secondly, however, this obviously does not amount to denying that we have experiences, or that our psychological concepts can't be grouped under a specific shared characteristic. As we have seen, it is indeed a shared feature of these concepts that they manifest an asymmetry between the first -and third-persons with respect to their justification. Yet, contrary to the phenomenological assumption, the fact that all these concepts display this asymmetry does not mean that they are all,for that very reason, concepts of experience - like, for example, 'seeing a color' or 'feeling a pain' are. In the latter cases, I am indeed living through experiences and I am consequently able to describe their experiential content or phenomenal features ('a blueish yellow', 'a throbbing pain'). By contrast, someone who has the intention to go on a holiday may experience all sorts of feelings (excitement, restlessness, ...), but nothing of what he experiences actually constitutes his intention. While we feel or experience emotions, we do not speak about 'experiencing' intentions. Neither expressions of belief or knowledge, nor expressions of intentions are accompanied by any particular 'what-it's-like-ness' or sensation - nor, for that matter, do they have to be in order to be authoritatively expressed:

'I intend' is not an expression of an experience. There is no cry of intention, any more than there is one of knowledge or belief. (Wittgenstein 1980: §179) 
Intent, intention, is neither an emotion, a mood, nor yet a sensation or image. It is not a state of consciousness. It does not have genuine duration. (Wittgenstein 1980: §178)

Similar observations hold with respect to the concepts of 'agency' and 'ownership' whose respective 'senses' are proposed to be disturbed or retained in experiences of TI.

On the one hand, to speak about my cognitive deliberations or thinking activities as things that I actively perform - leaving aside all various instances in which thought is obviously not an activity to begin with, but something that simply occurs, or something that may suddenly strike me, ... (for all these multifarious meanings of 'thought', see Anscombe 1981) - is not a matter of describing 'experiences of voluntariness' or of testifying about a subjective 'sense of agency'. To do something voluntarily rather means, for example, that I acted in the way I wanted to act, that I didn't feel obliged to act by someone else or because of some situation, that I can perform the action whenever I'm asked, or that it doesn't arise when I explicitly try to avoid it, etc. (see also Scott 1996). Experiences, by contrast, even in case of an 'agentive experience', are per definition not actively performed or done by me, but passively endured or enjoyed. While I might nonetheless actively try to bring them about - say, e.g., arousing a feeling of sublime anxiety by intentionally watching a horror movie -, they do not constitute my voluntary action of watching the movie, nor do I need to rely on them to know that I am acting voluntarily. A person's 'authority' with respect to his actions consists in his practical capacity to determine his course of action as an intentional agent, not in his knowledge about some volitional state of mind as an experiencing subject (see also Taylor 2010).

The same goes, on the other hand, for the fact of 'owning' thoughts or beliefs whose 'sense' is proposed to be necessary to ascribe thoughts and beliefs to myself. In order to speak about 'my' thoughts and beliefs, I do not have to consider how they are subjectively 'given' to me, I rather have to attend to the objective grounds or reasons for having them. To determine, for example, whether I think it will rain, I need to consult empirical facts about the weather, rather than experiential facts about my thinking experience. To claim that 'I think it will rain' is not a descriptive statement about my sense of owning a meteorological thinking state, but again an expressive statement about the possible prospect of raining. Yet, not only is a 'sense of ownership' unnecessary to speak of my thoughts and beliefs, it would in fact also make it impossible to do so - and this for two related reasons. On the one hand, in case offering my thoughts would amount to a descriptive statement in which I refer to myself as the experiential 
owner of these thoughts, I would be condemned to being able to speak only about myself - i.e., about my thoughts, my beliefs - and never about the objective condition of the weather. In this sense, all speakers would share the similar subjective or solipsistic predicament, and would consequently never be able to contradict or to agree with each other. On the other hand, if speaking about my thoughts were to consist in attributing thoughts to myself on the basis of my phenomenological experience, then who exactly would I be talking about? We may ask, regarding the subject who, in turning his attention to his thinking experience, knows that he thinks it will rain: does he also think it will rain? It would seem that such a subject would always occupy a spectral position of perpetual self-commentary with regard to his experiential self, hence always existing apart from his existence as an experiencer - as was indeed the paradoxical conclusion drawn by Sartre: "Thus the consciousness that says 'I think' is precisely not the consciousness which thinks. Or, rather, it is not its own thought which it posits by this thetic act" (2004: 6).

In summary, Wittgenstein's treatment of the authority of the first-person shows how the phenomenological emphasis on various forms of self-experience results from a misunderstanding of the expressive nature of this authority. In order to think and to speak my mind, I do not have to have an experience of my thoughts as 'self-generated' or as subjectively 'owned' - in fact, such an experience would actually undermine itself. Yet, if ordinary thinking is not a matter of having a sense of one's thoughts as one's own, then it is clear that reports of TI cannot be rendered intelligible by referring to the absence of such senses. In the following section, we will develop some general ideas on how experiences of TI could alternatively be understood without these phenomenological assumptions.

\section{Philosophy, schizophrenia and the paradoxes of subjectivity}

In the preceding sections, we have been critically considering one particular philosophical attempt to render reports of TI more comprehensible by appealing to different sorts of selfexperiences that are said to be disturbed in schizophrenia. In our introduction, we furthermore pointed out how this account exemplifies a more general tendency to view schizophrenia as substantiating, though in a negative or pathological way, certain philosophical assumptions regarding the essential nature of subjectivity and selfhood. Such a view is particularly evident in the phenomenological tradition, where schizophrenia has sometimes been likened to a form of unintentional or forced 'epochè' (see, e.g., Blankenburg 197; Stanghellini 2004), hence as laying bare the implicit structures of subjectivity that are normally assumed in everyday life. 
Whereas the phenomenological philosopher has to exert effort in order to penetrate to these foundational layers of self-experience, the schizophrenic individual is thought to be spontaneously confronted with them through their imminent disintegration or erasure. In this sense, one could say that both the philosopher and schizophrenic individual are concerned with the same foundational inquiry of what it means to be a 'self', although for different reasons and from opposite directions: whereas the philosopher attempts to get a clear theoretical view on what he already possesses, the schizophrenic individual seeks to existentially regain what he is acutely aware of as having lost.

While, in the preceding, we argued against such a foundational self-experience, there is, however, another way to exploit this analogy between philosophy and schizophrenia, one that may also get us further in understanding reports of TI. This alternative way of framing the analogy focuses less on the 'self', and its various putative qualities, as the shared object of schizophrenic and philosophical preoccupations, and rather on the contradictions and paradoxes that unavoidably arise as a result of such preoccupations. Sass $(1992 / 2017 ; 1994)$ and Kusters $(2020)^{5}$, in particular, have drawn attention to the fact that a similar self-generated paradox seems to underlie both the schizophrenic mindset and traditional philosophical reflections on the nature of subjectivity. In both cases, the paradox at issue arises from an intense and selfdirected preoccupation with the phenomenon of our own consciousness and our own thinking, a scrutinizing obsession that may befall both the schizophrenic individual, who may be fascinated and captivated by the nature of his or her own experience, and the philosopher of self-consciousness, who may be driven to reflect on the ever-elusive grounds of his or her own reflection.

With respect to schizophrenic experience, Sass (1992/2017) notes the peculiar tendency of such individuals to shift between two seemingly opposite or contradictory claims: on the one hand, they may display a grandiose and quasi-solipsistic sense of being the all-constituting and omniscient centers of reality; the exclusive owners of a strangely subjectivized world in which all alterities have been reduced to mere appearances for their own totalizing gaze. Yet, on the other hand, such solipsistic tendencies may just as easily turn into their exact opposites: instead of omnipotence, patients may claim a position of extreme passivity, of being under the spell of mysterious machines or transcendent mechanisms that have taken over control of their actions, will, and indeed (as in reports of TI) their own thoughts. Yet, it is not merely that schizophrenic

\footnotetext{
${ }^{5}$ See especially the concluding chapter 'Paradoxes of the reflexive' in Sass (1992) and chapter 13, 'Paradoxes: Philosophy and Madness Tied Up in Knots' in Kusters (2020).
} 
individuals may waver between these two opposite tendencies; they may even maintain both positions at the very same moment, as seemingly constituting but two incommensurate expressions of what is in essence one and the same insoluble experiential paradox. As Sass puts it: "While a schizophrenia patient is as likely to identify with God as with a machine, perhaps the most emblematic delusion of this illness is of being a sort of God machine, an all-seeing, all-constituting eye camera" (1992/2017: 270). In a more or less similar way, Kusters defines the "mystical-mad experience" in schizophrenia as essentially involved with "grasping and expressing the coincidentia oppositorum" (2020: 311), or again, as "the longing for the convergence and transcendence of paradoxical opposites" (2020: 544).

The initial relevance of these observations for our current discussion of TI should be readily apparent: not only are phenomenological concepts like a 'sense of mineness' or a 'feeling of agency', as we have previously argued, suspect on strictly philosophical grounds, they also seem unsuited to adequately grasp the nature of TI on more straightforward clinical grounds; that is, when the phenomenon of TI is brought back in this way to its proper paradoxical context. This is a context whereby, as Vygotsky put it, every symptom seems to be matched by a "countersymptom, its negative double, its opposite" (1987: 75) - or, in present terms, whereby the apparent loss of 'mineness' in TI and related passivity delusions is but the obverse of a coexisting 'sense of mineness' that is inflated, as in moments of unbridled omnipotence and solipsistic grandeur.

Here it may seem that Jaspers' verdict regarding the essential incomprehensibility of schizophrenic experience has reached its full climax. How, indeed, are we to empathically understand a state of mind that no longer seems governed by the principle of non-contradiction, or in which the 'owning' and 'disowning' of mental contents may apparently co-exist unperturbed? Must we simply give up on the project of understanding schizophrenic experience, and fall back on non-empathic forms of reductive explanation?

As a way out of this difficulty, Sass explores a revealing analogy with a similar aporetic antinomy prevalent in modern philosophical reflections on subjectivity. This typically modern turn towards subjectivity attempts to secure or understand the possibility and validity of knowledge, as in Descartes, Kant or Husserl, or else to foreground the possibility of autonomy and freedom, as in Fichte, Schelling or Sartre (for overviews, see Gasché 1997; Carr 1999; Seigel 2005). The common feature is a similar co-existence of two opposing developments. On the one hand, the subject emerges as the sovereign and constituting center of consciousness, the transcendental and self-determining ground on whose existence all else depends. The philosophical valuation of this form of subjectivity may resemble the solipsistic exhilaration 
that can accompany the schizophrenic appreciation of this side of the duality - as when Husserl, for example, speaks of the "discovery" of a "region of pure consciousness", "a primal region" to which all other regions of being "are relative and on which they all essentially depend" (1989: 171). Yet, on the other hand, this same subject also appears as itself a mere fact within this constituted universe, a spatiotemporal object determined and constrained by the same laws of nature that ordinarily subsume all other empirical entities. "Man", Kant writes, "is one of the appearances of the sensible world, and in so far one of the natural causes the causality of which must stand under empirical laws" (1971: A546f). Therefore, being a subject, in the modern philosophical tradition, means being confronted with the same incompatible duality that may bewilder schizophrenic individuals: i.e., that of simultaneously existing as a subject for the world, as the condition of its possibility, but also as a mere object in this world, a contingent and determined entity within this field of appearance.

Yet, a further important aspect of this analysis is that, similar to the schizophrenic combination of these two incompatible positions, this philosophical duality does not merely entail two opposing yet independent views on the same phenomenon. Instead of being merely externally opposed, it was also recognized that the subjective and objective poles of the duality are in fact two dialectical moments of the same reflexive turn, in the sense that the very effort to assert and to promote the subject as the transcendental 'owner' of the world's experience ultimately engenders this subject's own objectification and alienation. The neo-Kantian Natorp, for example, emphasized how every reflexive attempt to attain and to capture the transcendental first-person perspective has the effect of "killing" or "mortifying" this pristine form of subjectivity, of reducing it to yet another objectified representation within the field of awareness: "one apparently never grasps the subjective, as such, in itself. On the contrary, in order to grasp it scientifically, one is forced to strip it of its subjective character. One kills subjectivity in order to dissect it, and believes the life of the soul is on display in the result of the dissection! (Natorp 1912: 102-103). Hence, similar to the paradoxical combination of the quasi-solipsistic and passivized positions in schizophrenia, we encounter a same impossible fusion of opposites in the philosophy of the subject: the very effort to subjectivize the experience of the world, and to reflexively attend to this first-person perspective, has the effect of objectifying this subjective dimension as something that appears alienated and different from the subject.

To conclude, what are the implications of this analysis of the reflexive paradoxes of schizophrenia and philosophy for our present discussion on how to understand reports of TI?

First, if the analogy is more than a fortuitous coincidence, than this means that certain key symptoms or experiences of schizophrenia are better understood as different dialectical 
moments in a more general and overarching paradox. Viewed from this perspective, the fact that the philosophical literature has nearly exclusively focused on the analysis of TI as one of these symptoms should be seen as something that is not merely artificial, but also as significantly distorting the phenomenon that is to be explained, and by implication, the form such an explanation might take. Secondly, with respect to this explanation, we argued that, rather than in terms of the presence or absence of various self-experiences which would normally be enjoyed in our ordinary conscious lives, reports of TI can be better understood as giving voice to one side of the paradox that arises when consciousness attempts to turn back at itself in order to be present, as it were, at its own engendering and creation. The reflexive attempt to capture or seize upon one's own epistemological centrality, to step outside one's first-person perspective in order to see it as a first-person perspective, is but the immediate obverse of the objectification or reification of the mind. TI is then, rather than a mute or passively endured experiential loss, the epitome of a hyper-conscious mind captivated by the paradoxes of its own making.

\section{References}

Anscombe E (1981). Metaphysics and the Philosophy of Mind. Collected Papers, Volume 3. Minneapolis: University of Minnesota Press.

Blankenburg W (1971). Der Verlust der natürlichen Selbstverständlichkeit. Stuttgart: Enke.

Bovet P \& Parnas J (1993). Schizophrenic delusions: A phenomenological approach. Schiz Bull; 19(3): 579-597.

Billon A (2013). Does consciousness entail subjectivity? The puzzle of thought insertion. Philos Psychol; 26(2): 291:314.

Bortolotti L \& Broome MR (2009). A role for ownership and authorship in the analysis of thought insertion. Phenomenology \& Cog Sci; 8(2): 205-224.

Campbell J (1999). Schizophrenia, the space of reasons, and thinking as a motor process. The Monist; 82: 609-625.

Campbell J (2001). Rationality, meaning, and the analysis of delusion. Phil, Psych \& Psychol; 8: $89-100$.

Carr D (1999). The Paradox of Subjectivity: The Self in the Transcendental Tradition. Oxford University Press.

Coliva A (2002). Thought insertion and immunity to error through misidentification. Phil, Psych \& Psychol; 9(1): 27-34.

Dennett D (1991). Consciousness Explained. New York, NY: Back Bay Books/Little, Brown and Company.

Depraz N (2003). Putting the epoché into practice: schizophrenic experience as illustrating the phenomenological exploration of consciousness. In: Fulford KWM, Morris K, Sadler J \&

Stanghellini G (eds) Nature and Narrative: An Introduction to the New Philosophy of Psychiatry. Oxford: Oxford University Press, 187-198.

Descombes V (2004). Le complément de sujet. Enquête sur le fait d'agir de soi-même. Paris: Gallimard. 
Feyaerts J \& Vanheule S (2017). Hij of het (ding) denkt, niet ik: Frith over verbale hallucinaties. Tijdschrift Fil; 79(2): 313-342.

Feyaerts J, Kusters W, Van Duppen Z, Vanheule S, Myin-Germeys I \& Sass L (2021). Uncovering the realities of delusional experience: a qualitative phenomenology study in Belgium. Lancet Psychiatry 8(9): 784-796.

Gallagher S (2000). Self-reference and schizophrenia. In: Zahavi D (ed) Exploring the Self: Philosophical and Psychopathological Perspectives on Self-experience. John Benjamins Publishing Company, 203-239.

Gallagher S (2015). Relations between agency and ownership in the case of schizophrenic thought insertion and delusions of control. Rev Philos Psychol; 6: 865-879.

Gallagher S \& Zahavi D (2005/2014). Phenomenological approaches to self-consciousness. The Stanford Encyclopedia of Philosophy. http://plato.stanford.edu/entries/self-consciousnessphenomenological/.

Gasché R (1986). The Tain of the Mirror. Derrida and the Philosophy of Reflection. Harvard University Press.

Henriksen M, Parnas J \& Zahavi D (2019). Thought insertion and disturbed for-me-ness (minimal selfhood) in schizophrenia. Conscious Cogn; 74: 102770.

Henry M (1973). The Essence of Manifestation. The Hague: Martinus Nijhoff.

Humpston C \& Broome MR (2016). Perplexity. In: Stanghellini G. \& Aragona M. (eds) An Experiential Approach to Psychopathology: What is it like to suffer from mental disorders?

Berlin: Springer, 245-264. Psychiatric Q; 89(4): 957-968.

Husserl E (1976) [1913]. Ideen zu einer reinen Phänomenologie und phänomenologischen Philosophie, book 1, Allgmeine Einführung in die reine Phänomenologie, ed. K Schuhmann, Husserliana 3/1-2. The Hague: Martinus Nijhoff.

Husserl E (1989). Ideas Pertaining to a Pure Phenomenology and to a Phenomenological Philosophy. Second Book: Studies in the Phenomenology of Constitution. Dordrecht: Kluwer Academic Publishers.

Jaspers K (1963). General Psychopathology. Manchester: Manchester University Press.

Kant I (1971). Kritik der reinen Vernunft. Frankfurt am Main: Felix Meiner.

Kusters W (2020). A Philosophy of Madness. The Experience of Psychotic Thinking. The MIT Press.

López-Silva P (2018). Mapping the psychotic mind: a review on the subjective structure of thought insertion.

Natorp P (1912). Allgemeine Psychologie nach kritischer Methode. Tübingen: J.C.B. Mohr.

Narboux JP (2019). Pensées en première personne et cogitationes cartésiennes. In Ong-VanCung KS (ed) Les formes historiques du Cogito. Paris: Classiques Garnier, 311-350.

Nietzsche F (1886). Beyond Good and Evil (Jenseits vond Gut und Böse). Leipzig: Naumann.

Nordgaard J, Henriksen MG, Berge J \& Nilsson LS (2019). First-rank symptoms and selfdisorders in schizophrenia. Schiz Res; 210: 306-307.

Parnas J \& Zahavi D (2000). The link: Philosophy-psychopathology-phenomenology. In: Zahavi D (ed) Exploring the Self. Philosophical and Psychopathological Perspectives on Self-experience. John Benjamins Publishing Company, 1-18.

Ratcliffe M (2008). Feelings of Being: Phenomenology, Psychiatry and the Sense of Reality. Oxford: Oxford University Press.

Ratcliffe M \& Wilkinson S (2015). Thought insertion clarified. J Consc St; 22(11-12): 246-269.

Roessler J (2013). Thought insertion, self-awareness, and rationality. In: Fulford KWM, Davies M, Gipps RGT, Graham G, Sadler J, Stanghellini G \& Thornton T (eds) The Oxford Handbook of Philosophy and Psychiatry, 658-672.

Sartre JP (2004). The Transcendence of the Ego: A Sketch for a Phenomenological Description. London, New York, NY: Routledge. 
Sass L (1992/2017). Madness and Modernism. Insanity in the Light of Modern Art, Literature, and Thought (revised edition). Oxford University Press.

Sass L (1994). The Paradoxes of Delusion. Wittgenstein, Schreber, and the Schizophrenic Mind. Cornell University Press.

Schneider K (1959). Clinical Psychopathology. Grune \& Stratton: New York.

Schoemaker S (1968). Self-reference and self-awareness. J of Phil; 65: 556-579.

Scott M (1996). Wittgenstein's Philosophy of Action. The Philosophical Quarterly; 46(184): 347-363.

Seigel J (2005). The Idea of the Self. Thought and Experience in Western Europe since the Seventeenth Century. Cambridge University Press.

Stanghellini G (2004). Disembodied Spirits and Deanimated Bodies: The Psychopathology of Common Sense. Oxford: Oxford University Press.

Strassberg D (2014). Der Wahnsinn der Philosophie. Verrückte Vernunft von Platon bis Deleuze. Chronos Verlag.

Strawson G (2003). Mental ballistics or the involuntariness of spontaneity. Proc Aristot Soc; 103(3): 227-257.

Taylor C (2010). Hegel and the philosophy of action. In Laitin A \& Sandis C (eds) Hegel on Action. Palgrave-Macmillan, 22-41.

Vygotsky LS (1987). The psychology of schizophrenia. Soviet Psychology 26: 75.

Wittgenstein L (1980). Remarks on the Philosophy of Psychology. Volume 2. Oxford: Blackwell.

Wittgenstein L (2009). Philosophical Investigations. $4^{\text {th }}$ Edition. Oxford: Wiley-Blackwell.

Woods A (2011). The Sublime Object of Psychiatry. Schizophrenia in Clinical and Cultural Theory. Oxford University Press.

Zahavi D (2014). Self and Other. Exploring Subjectivity, Empathy, and Shame. Oxford University Press. 
